\title{
O mural de Eduardo Kobra em Santa Maria: diálogo ou imposição no espaço urbano
}

\author{
The mural of Eduardo Kobra in Santa Maria: dialogue or imposition \\ in urban space
}

Mariete Tasquetto Uberti ${ }^{i}$

\section{Resumo}

Este artigo é um excerto da dissertação de Mestrado realizada junto ao Programa de Pósgraduação em Artes Visuais/UFSM, concluído em 2014. O qual versa sobre a Arte Pública em Santa Maria a partir de uma análise da obra de Eduardo Kobra com relação à arte local e os principais influenciadores no/para o campo da Arte Pública. Em cuja perspectiva, sobre a arte local, embasei-me em Folletto e Bisognin (2001). O artista é abordado pelo viés de sua relação com a arte nos espaços urbanos desde sua inserção no respectivo campo através da pichação aos projetos desenvolvidos na atualidade. A partir da contextualização da obra de Kobra em Santa Maria, objetivou-se fazer uma análise sobre suas reverberações para/na Arte Pública e a comunidade artística, mais especificamente aos grupos de artistas que produzem suas obras nos espaços urbanos municipais. Além de discorrer sobre as relações com o público e com os fomentadores de obras nos espaços públicos e seus condicionamentos ao selecionar obras e artistas para expor. O estudo, no decorrer das entrevistas e da análise do panorama local, mostrou-se pertinente pelas reflexões e questões que a obra trouxe a tona sobre o cenário artístico diante do embate entre as artes visuais e a atuação do poder público e das interações sociais que a obra possibilitou entre a Arte Pública e o público a partir de um reconhecimento da história local e sua arte.

\section{Palavras-chaves}

Arte Pública, Eduardo Kobra, Obra, Comunidade artística Santa-mariense.

\begin{abstract}
This article is an excerpt from Master's thesis conducted at the Graduate Program in Visual Arts / UFSM, completed in 2014. Which is about the Public Art in Santa Maria from an analysis of Eduardo Kobra's work in regarding local art and the main influencers in / to the field of Public Art. In whose perspective on the local art, it was based in Folletto and Bisoning (2001). The artist is approached by the angle of his relationship to art in urban spaces since his inclusion in the respective field through graffiti to projects developed at present time. From the contextualization of Kobra's work in Santa Maria, it was aimed to make an analysis of his reverberations to / on Public Art and the artistic community, more specifically to groups of artists who produce their works in the municipal urban spaces. In addition to discuss relations with the public and with the promoters of works in public spaces and their constraints when selecting works and artists to exhibit. The study, in the course of the interviews and the local view analysis, proved to be relevant by the thoughts and questions that the work brought to light on
\end{abstract}

Revista Digital do LAV - Santa Maria - vol. 8, n. 2, p. 190 - 213. - mai./ago. 2015 ISSN 1983 - 7348 http://dx.doi.org/10.5902/1983734819872 
the art scene before the clash between the visual arts and the performance of government and social interactions that the work allowed between Public Art and the public from a recognition of the local history and its art.

\section{Keywords}

Public Art, Eduardo Kobra, work, Santa-Mariense artistic community.

\section{Introdução}

A pintura mural de Eduardo Kobra, realizado em Santa Maria, Rio Grande do Sul ,é base para análise das possíveis interações que a mesma propicia, seja no campo das artes, nas relações que o artista produz com ou no contexto onde suas obras são instaladas, como na cidade em estudo, seja ele local e/ou espacial. Cuja proposição para o referido texto, originou-se de parte da pesquisa de Mestrado, defendida em 2014 junto ao Programa de Pós-graduação em Artes Visuais PPGART/UFSM, intitulada "O mural de Eduardo Kobra em Santa Maria: Uma relação com a Arte Pública", sob a orientação do profo Dro Lutiere Dalla Valle.

Para tal premissa, será realizada uma contextualização do artista Eduardo Kobra, sua produção vinculando-a ao lugar, a Arte Pública santa-mariense. A qual requereu uma aproximação direta com o artista, através de uma entrevista realizada em julho de 2013, como ele percebe a si mesmo em processo, sua relação com a população e com a Arte Pública e as escolhas para essas produções. Como ele mesmo trata: "uma obra deslocada de seu espaço de origem não teria sentido algum e meu maior interesse é dar sentido às coisas, aos espaços e as pessoas que vivem e transitam por eles" (KOBRA, 2013) ${ }^{1}$. O artista no projeto Muros da Memória propõe oportunizar um elo entre o passado e o presente nos espaços onde seus murais são produzidos.

A partir da análise da obra de Kobra na cidade, objetiva-se no decorrer do texto contextualizar sobre as interações que a obra propiciou, seja entre público e obra, comunidade artística e poder público, passado e presente. Onde os embates entre o poder público e a comunidade artística se fizeram/fazem presente no que concerne a olhares distintos sobre a arte, que provocaram/provocam ponderações que ainda são foco de discussão. As quais afloraram com a instalação da obra, que colaborou para que a Arte Pública e os artistas locais buscassem alternativas de diálogo, como no caso do

\footnotetext{
${ }^{1}$ Adaptação de parte do texto da entrevista de Kobra cedida à pesquisadora em jul. 2013.
}

Revista Digital do LAV - Santa Maria - vol. 8, n. 2, p. 190 - 213. - mai./ago. 2015 ISSN 1983 - 7348 http://dx.doi.org/10.5902/1983734819872 
grupo Arte Pública, ou de outros espaços de discussão e exposição das obras na cidade, como exemplo o evento Arte Ocupa\#SM².

Na primeira parte irei discorrer sobre o artista e suas obras, enfatizando o projeto Muros da Memória, em cuja linha de pesquisa encontra-se a obra em Santa Maria, direcionado as questões referentes à memória em sua poética, para tal premissa, amparei-me no próprio conceito dado pelo artista para o termo e de autores oriundos da sociologia e da filosofia que tratam do tema, entre eles Bergson (2011); Pelbart (2010).

O trabalho de Eduardo Kobra em Santa Maria partiu da deliberação do poder público. Que fazia parte de um processo de revitalização da cidade, juntamente com outras obras que foram expostas em outros sítios e a revitalização da Avenida Rio Branco ${ }^{3}$, que objetivavam uma aproximação com o público e deste com a "memória local". Nesse contexto, busco situar o artista e o espaço da pesquisa com o trabalho de Kobra. Inicialmente discorro sobre as possíveis relações e interações, seja no âmbito espacial e temporal da obra, tanto da relação presente e passado, quanto do espaço onde a mesma é exposta. Em seguida, articulo o processo e a reverberação da obra ao contexto artístico, cultural e educacional local, com a comunidade artística.

Para tanto, utilizarei como principais marcos teóricos, Peixoto (2009, 2012), que aborda as vinculações entre obra e espaço, exemplificando com alguns projetos e obras desenvolvidas nesses espaços, não somente obras fixas, como murais, esculturas, mas também, instalações, performances, intervenções, criação de projetos em grupos de artistas para lugares específicos e Alves (2011), que trabalha com o projeto da 5 a Bienal do MERCOSUL, direcionado às produções de obras criadas para o lugar, em espaços públicos, onde foram convidados quatro artistas para criarem obras que foram instaladas na Orla do Guaíba, em Porto Alegre-RS. Neste trabalho, ele discorre sobre as associações dos conceitos de arte e público, suas aproximações e divergências.

As autoras que oferecem uma aproximação com a arte produzida em Santa Maria são Foletto e Bisognin (2001) e Foletto (Org., 2008), por tratarem de forma abrangente a

\footnotetext{
${ }^{2}$ Esse grupo começou logo que a Rebeca Stumm veio do doutorado dela, nos primeiros meses ela já começou a mobilizar o grupo com os seus orientandos do PPGART. Ainda na época das férias do primeiro para no segundo semestre de 2011 teve o primeiro evento que era o "Passando 24 horas na casa do Manoel Ribas" [...] (MACHADO, 2013); Eu acho interessante esse projeto por estar buscando espaços comuns para as exposições de arte, outro por estar promovendo exposições que não são exposições que têm outro tipo de proposta, que é uma proposta da modificação da adaptação e do diálogo. Que não tem um planejamento, oportunizando a chance de se modificar, por trazer artista de fora e não só os artistas daqui (VAZ, 2013).

${ }^{3}$ Foi uma imagem desta avenida que o artista pintou no mural em Santa Maria.
}

Revista Digital do LAV - Santa Maria - vol. 8, n. 2, p. 190 - 213. - mai./ago. 2015 ISSN 1983 - 7348 http://dx.doi.org/10.5902/1983734819872 
arte local, situando um panorama artístico das influências que reverberaram nas produções e nos principais nomes no que tange às obras nos espaços públicos da cidade.

A pesquisa qualitativa, nesse contexto, nos dispõe traçar analogias entre processo e conjunto tanto cultural, social ou histórico, que pode envolver questões relacionais, como no caso das obras de Kobra, que, além de possibilitarem uma análise de representação formal, propiciam, principalmente, interpretar os vínculos que são criados no seu contexto com a obra de arte e o local, entre passado e presente, e ainda, entre artistas que têm suas poéticas voltadas para os espaços públicos.

Para os estudos sobre o artista e a arte em Santa Maria, utilizei-me dos diários de artista, projetos, imagens fotográficas e as entrevistas concedidas por Kobra (que foram acessadas em páginas na internet) e da cedida a mim em julho de 2013, por evidenciarem o contexto entre artista e obra, as influências que o levaram a produção das mesmas. Assim sendo, entendemos que através do diálogo e de uma aproximação, conhecendo diretamente o artista poderia ter um embasamento mais significativo ao abordar os processos criativos na poética das obras. Nesse sentido. Considerou-se que os relatos orais/entrevistas, também, se constituíram em instrumentos de apoio fundamental à pesquisa ao possibilitarem compreender outras "faces do passado que não aqueles apresentados em documentos históricos" ${ }^{4}$ (THOMPSON, 2002, p. 18). Além da entrevista com Kobra, entrevistas com artistas locais, que têm trabalhos desenvolvidos nos espaços públicos da cidade e um representante do poder público, por considerar relevante analisar e conhecer a opinião tanto da comunidade artística local, quanto do poder público.

As entrevistas ajudaram a entender como se deu o processo de inserção do mural de Kobra em Santa Maria e sua relação direta com a Arte Pública local, seja por parte do poder público, seja pela visão dos artistas entrevistados e mesmo pelo próprio artista quando analisa a situação ${ }^{5}$ da obra em 2013, com relação ao público.

\footnotetext{
${ }^{4}$ Quando me refiro a documentos históricos, me reporto a fontes documentais, como artigos em jornais, imagens das obras, textos produzidos e publicados pelos próprios artistas em outro momento.

Quando me refiro a documentos históricos, reporto- me a fontes documentais, como artigos em jornais, imagens das obras, textos produzidos e publicados pelos próprios artistas em outro momento. Uma vez que ao pensar em utilizar a entrevista tenho como objetivo primordial direcioná-la às questões e objetivos desta pesquisa.

5 "Eu não sei se ele ainda permanece?... E tem uma pichação também não é?...E a pichação que tinha no meio, na parte de baixo é grande?... Há alguns dias atrás tivemos contatos para ver da possibilidade de uma restauração, mas até agora não deu. Em algumas ocasiões eu estava viajando. Enfim, até agora a gente não conseguiu ainda... O ideal é que seja restaurado o mais rápido, porque com o tempo vai apagando" (KOBRA, Entrevista concedida à pesquisadora em jul. 2013).
}

Revista Digital do LAV - Santa Maria - vol. 8, n. 2, p. 190 - 213. - mai./ago. 2015 ISSN 1983 - 7348 http://dx.doi.org/10.5902/1983734819872 


\section{Eduardo Kobra: da pichação à pintura mural}

Eduardo Kobra, como ficou conhecido, é autodidata e teve seus primeiros contatos com a arte urbana na segunda metade da década de 1980, quando começou a realizar seus primeiros trabalhos na periferia de São Paulo. Seu primeiro contato com a pintura foi aos 12 anos, quando usou, pela primeira vez, uma lata de spray para pichação. Pouco tempo depois, começou suas pesquisas em grafite, que foram influenciados pelos elementos do hip hop, quando fazia bonecos e letras típicas dessa corrente e usava basicamente o spray (Adaptação da entrevista cedida à pesquisadora em jul. 2013).

Em 1995 fundou o Stúdio Kobra com uma equipe de doze artistas. Em 2005, criou o projeto Muros da Memória, influenciado pela visita realizada à uma exposição de fotografias, que mostrava casarões e árvores da Avenida Paulista, da década de 1920, na cidade de São Paulo. Como relata o próprio Kobra "percebi que quase tudo havia se perdido, daí a ideia de reconstruir artisticamente e pintar o que eles haviam demolido, criando uma janela para uma cidade que já não existe mais" (KOBRA, Entrevista a CUNHA, 2012). Esse trabalho impulsionou sua carreira e o fez ficar conhecido no Brasil e em parte do estrangeiro, apresentando um muralismo particularmente seu, com uma poética voltada à memória urbana, por meio de fotos antigas do cotidiano das cidades. Recebeu influência de muralistas como o mexicano Diego Rivera (1886-1957) e o brasileiro Di Cavalcanti (1897-1976), dois expoentes da arte mural do século XX, além do norte-americano Jean-Michel Basquiat (1960-1988) e de Kurt Wenner.

Os murais do artista são produzidos nos espaços urbanos das cidades, em viadutos, túneis, fachadas de prédios privados e públicos (pois considera a cidade e seu espaço urbano como o ateliê e os muros como telas). Espaços estes, que servem de lugar tanto para a exposição, quanto para sua poética artística, às quais estão ligadas à memória do lugar, como aborda Cunha, "assim como em outras obras, o artista plástico não chegou ao espaço com a ideia pronta. Inquieto com o passado, seu ponto de partida é a pesquisa da memória da cidade em livrarias, museus e arquivos históricos" (2012, s/p) e "pela aquisição de livros que o auxiliem em suas pesquisas" (KOBRA, 2013).

O que o diferencia dos demais artistas é a sua temática e técnica, bem como as ideias vinculadas aos conceitos de memória e a maneira como entrelaça seu trabalho com o

Revista Digital do LAV - Santa Maria - vol. 8, n. 2, p. 190 - 213. - mai./ago. 2015 ISSN 1983 - 7348 http://dx.doi.org/10.5902/1983734819872 
local, partindo das imagens de cenas do cotidiano das cidades que recebem suas obras. Kobra não impõe um olhar seu, a partir de imagens de outros locais, mas busca dialogar entre a história atual e o passado. Como discorre o próprio artista,

A questão da memória tem a ver com o resgate da história das cidades, onde reproduzimos o trabalho, com relação à desse lugar. Um dos objetivos é reconstruirmos artisticamente algo que a cidade não preservou e que os mais jovens não têm conhecimento... esses dias mesmos, eu estava andando pela Avenida Paulista e vi um casarão antigo, abandonado. A ideia é despertar essa conscientização da importância da preservação do patrimônio histórico da cidade. É uma das partes do trabalho, ao reconstruir artisticamente, muitas vezes acabamos reconstruindo esse patrimônio, que muitas vezes não foi preservado... Quando levamos essas imagens para o muro, estamos disponibilizando seu acesso a milhões de pessoas e jovens que muitas vezes não imaginavam, não tinham conhecimento (KOBRA, Entrevista cedida à pesquisadora em jul. 2013).

Da mesma forma, sugere que as memórias suscitadas pela obra possam ser lembradas ou mesmo "revividas" por aquelas pessoas que viverem naquele tempo e estimular um interesse daqueles que não conhecem essa parte da história local de cada cidade que recebe seus murais. $O$ artista, nesse sentido, não somente disponibiliza, por meio de seus murais, o acesso a essas imagens, como também se integra a elas, quando fala de uma busca ao passado, a um resgate que, ligado a cidade de São Paulo, diz respeito a ele próprio, em se reconhecer e conhecer a história da cidade que habita.

As memórias e histórias só podem ter um sentido, significado, tanto individual quanto coletivamente quando imbricadas a fatos e momentos que tiveram e/ou ainda têm relevância para a formação social ou histórica de cada sujeito. Essas memórias produzidas por esses indivíduos ou grupos são carregadas de sentimentos oriundos dos fatos passados, que se deixam transparecer nos relatos desses tempos, seja por suas representações simbólicas, culturais, individuais, sociais e coletivas (DIEHL, 2006). Pelbart (2010) fala de uma constante mudança e reconfiguração dessa memória, que a cada relembrança acrescenta modificações, ou como fala o autor: "A imagem mais adequada é a prosaica, sugerida por Michel Serres: o lenço. A cada vez que assoamos o nariz, enfiamos o lenço no bolso de um modo novo, remanejando as distâncias entre os diversos pontos nele assinalados" (p.19). A cada nova experiência do eu individual ou coletivamente, são possíveis novas análises e alterações no contexto da memória, pois

Revista Digital do LAV - Santa Maria - vol. 8, n. 2, p. 190 - 213. - mai./ago. 2015 ISSN 1983 - 7348 http://dx.doi.org/10.5902/1983734819872 
como discorrem em seus textos Bergson (2011) e Catroga (2009), ela é fruto do presente que influencia as lembranças do passado. Uma memória que não é pura, nem linear, mas que faz parte do sujeito, através de imagens, indiretamente selecionadas do passado, ou criadas em sua mente pelas histórias contadas por outras pessoas ou mesmo lidas em livros ou diários de família.

As obras do projeto Muros da Memória são produzidas a partir de relatos visuais e fragmentos de memória que não foram vivenciados pelo artista, mas que ficaram registrados em fotografias de época, seja em acervos pessoais ou em acervos de poderes públicos. Os murais de Kobra viabilizam esse acesso a algumas dessas imagens, potencializando sua visualidade ao trazer à tona as lembranças de um tempo passado. Além de objetivar representar o entrelaçamento entre obra e espaço, entre obra e público. Mesmo que este público não seja um apreciador da arte, pode criar uma identificação pela imagem realista de seus murais.

O artista e sua equipe já produziram obras em diversas cidades brasileiras e países estrangeiros, mas seu maior ateliê é a cidade de São Paulo, onde nasceu e reside atualmente, como ele mesmo comenta: "Existe uma mensagem oculta, algo subliminar neste mural, que é justamente o meu amor incondicional por São Paulo, cidade onde nasci e vivo há 35 anos, e que é à base de tudo o que faço artisticamente" (KOBRA, entrevista a GONTOW, 2012, s/p). A maior parte dos seus trabalhos retrata a São Paulo da primeira metade do século passado. "A ideia é resgatar um pouco da memória que se perdeu" (Idem, 2013).

Observei nas entrevistas concedidas pelo artista, o quanto destaca em suas obras a relação que tem com a capital paulista. Seu sentimento se faz presente em seus murais espalhados pela cidade. Na série Muros da Memória, Kobra representa as mudanças ocorridas desde o início do século XX à atualidade. Essas imagens já foram representadas em centenas de murais pela metrópole paulistana, além de obras espalhadas pelo restante do país.

Seus trabalhos são reconhecidos pelas imagens hiper-realistas com as quais o público se identifica. O artista costuma fotografar todas as suas obras, contendo um acervo de mais de três mil imagens (Kobra, 2013). A arte da rua, segundo ele, "é uma arte efêmera, onde não se pode prever seu tempo de duração, por isso, costumo registrar tudo" (Idem).

Revista Digital do LAV - Santa Maria - vol. 8, n. 2, p. 190 - 213. - mai./ago. 2015 ISSN 1983 - 7348 http://dx.doi.org/10.5902/1983734819872 
A partir de 2011, criou o projeto chamado "Greenpincel", onde busca denunciar os descuidos do homem com a natureza, entre outras, a matança dos animais, buscando assim, criar obras que despertem a atenção do observador, fazendo referência a todos os tipos de violência à natureza. Segundo Kobra, a arte não tem a função de embelezar os espaços, mas de criticar, chamar a atenção para a realidade. O artista propõe com seus murais potencializar questões que estão presentes na atualidade, como a valorização do patrimônio histórico, as questões ambientais.

Kobra tem trabalhos seus em vários países e no Brasil, por várias cidades. No entanto, ainda enfrenta dificuldades para a produção de seus murais, entre elas está liberação/autorização dos espaços/muros para suas pinturas, os poucos espaços que consegue são por tempo indeterminado. Em alguns deles, Kobra já teve pintado em torno de dois a três murais seus. Um exemplo é o muro na Rua Henrique Schaumann, em Pinheiros, onde em 2006 realizou o mural em homenagem à Música típica do Nordeste, e que recebeu no mesmo muro em 2007, a pintura Largo de Pinheiros dos anos 20, em comemoração aos 447 anos da cidade (TAMOTO, 2007).

Segundo o artista o importante, é poder produzir suas obras, mesmo que para isso tenha que utilizar o mesmo muro diversas vezes e assim pintar por cima de outros trabalhos. 0 que fica é o registro fotográfico das obras, pois muitas se perderam pelo vandalismo, outras pela falta de uma política de preservação por parte das autoridades e outras, ainda, pelo desinteresse das empresas que as adquiriram, repintando as paredes. Situações estas que vêm ao encontro de uma afirmação do artista, "a arte de rua é uma arte efêmera, mas quanto mais durar uma obra, mais pessoas poderão ter contato" (Kobra, 2013).

Kobra, como grande parte dos artistas, está sempre fazendo escolhas, delimitando espaços, imagens, relacionando contextos, ao deliberar pela pintura mural. O mesmo trata do assunto em várias de suas entrevistas, destacando que a pintura mural é legalizada, "Hoje em dia eu faço pintura mural porque é permitido, através da influência que eu tive da cultura hip hop" (KOBRA, 2013). A qual também, Ihe proporciona uma notoriedade, não só no Brasil, mas também em outros países, onde já produziu várias obras e participou de exposições. Em seus murais, questiona a relação das cidades com suas memórias, destacando imagens de seus centros no passado, através de suas pinturas de imagens de época que se destacam pela estética da obra.

Revista Digital do LAV - Santa Maria - vol. 8, n. 2, p. 190 - 213. - mai./ago. 2015 ISSN 1983 - 7348 http://dx.doi.org/10.5902/1983734819872 


\section{A arte em Santa Maria: uma história em construção}

A transição entre a arte decorativa para uma arte com características modernas em Santa Maria se deu mais tardiamente que no restante do país. As mudanças só começaram a ocorrer com a fundação do Curso de Belas Artes (UFSM), na década de 1960, pois, até a sua criação, as produções em pintura, escultura, eram direcionadas ao comércio. Com a criação do referido curso, novas possibilidades foram se apresentando no circuito artístico local, ou como abordam Foletto e Bisognin (2001), "ao lado do mundo desenvolvido e tecnológico das grandes cidades e capitais e, relacionado com o progresso, convivia e convive, no Brasil, um outro mundo, muitas vezes ligado ao apego, às tradições e ao passado" (2001, p. 17). Com percepções ligadas aos paradigmas relacionados à arte moderna, através dos artistas que vieram para a cidade, a fim de ministrar as disciplinas. Paralelamente, os acadêmicos buscaram atualizar seus conhecimentos ao que estava sendo pesquisado no contexto artístico nacional, e isso proporcionou, aos poucos, um avanço no campo da pesquisa em artes visuais na cidade.

No que concerne ao campo da Arte Pública, a incorporação das primeiras esculturas e murais, estavam integrados às poéticas pessoais dos artistas libertando-se do cunho comercial, que delimitava o cenário local. O curso, desse modo, buscava aproximar-se das pesquisas que estavam acontecendo nos principais centros do país (Idem, 2001).

Tais estudos eram de cunho modernista, e, em parte, tinham como objetivo produzir obras para os espaços públicos da cidade. Ou seja, "a escultura moderna passou de uma lógica do lugar histórico, o monumento ou estátua, para a da forma autônoma - o objeto sem lugar, absorvendo o pedestal que indicava sua implantação num local" (PEIXOTO, 2012, p. 20).

Segundo Alves (2011) o termo Arte Pública só foi nomeada, no contexto artístico internacional, na década de 1960 para designar a arte moderna e contemporânea desenvolvida e inserida em lugares públicos das cidades - fora dos museus e galerias de arte, que até então eram os delimitadores de inserção dos artistas e das obras na rede das artes, em obras in situ e em intervenções contemporâneas nesses lugares. Naquele momento, as obras modernas que eram criadas para os espaços públicos por artistas reconhecidos, passaram a acontecer sem necessariamente depender da interação do espectador ou apreciador da obra. Paralelamente, intervenções contemporâneas se

Revista Digital do LAV - Santa Maria - vol. 8, n. 2, p. 190 - 213. - mai./ago. 2015 ISSN 1983 - 7348 http://dx.doi.org/10.5902/1983734819872 
inseriram no campo da Arte Pública e assim usufruíram desses sítios para suas produções artísticas.

Os artistas, a partir daquele contexto, passam a direcionar suas obras tanto para serem expostas em museus, quanto a um reconhecimento da crítica, além da estética da obra, ganhando evidência a poética, a relação entre obra e espaço, obra e momento de vivência e interação com o que pode ser produzido junto aos elementos do conjunto onde a obra acontece.

Em Santa Maria, no entanto, essas pesquisas só vieram a ocorrer no final da década de 1970 e início de 1980, com a vinda dos professores Luis Gonzaga Gomes (1940-) e Silvester Peciar Basiaco (1935-), que se destacaram e influenciaram nas pesquisas artísticas direcionadas à escultura pública. Foi a partir desse período que o cenário urbano começou a ganhar significativamente um número de obras em escultura e murais modernos, pensados para os espaços públicos (FOLETTO E BISOGNIN, 2001).

Na década de 1990, as pesquisas em esculturas continuaram vinculadas ao Curso de Belas Artes. A estilização das obras foi se intensificando com tendências ao abstracionismo, havendo um desprendimento da relação "objeto representado e obra de arte", o que pode ser evidenciado pelas obras expostas no espaço do campus da UFSM.

Entre o final da década de 1990 e início dos anos 2000, as pesquisas no campo artístico de obras para a Arte Pública continuaram ocorrendo junto ao curso de Artes da UFSM. E, paralelamente, foram organizando-se grupos de artistas, os quais desenvolveram intervenções, performances, produção de obras efêmeras e instalações nos espaços públicos da cidade. Esses grupos também foram criados no curso de Artes, sob a orientação de seus professores. A partir desses, outros grupos de artistas ou coletivos foram sendo organizados, paralelamente a eles, formam criadas intervenções esporádicas, pelos estudantes do curso de Artes, juntamente com outros acadêmicos da UFSM. Como é exemplo o grupo Arte Pública,

O grupo começou em 2008, há cinco anos e meio, esse grupo formalizado. As pesquisas já vinham de cada um e começaram em 2000, há quatorze anos, estamos pesquisando, investigando. Com o grupo em 2008, em Arte Pública, de forma mais organizada, mais coletiva, que dá outra dimensão para o trabalho (CHAGAS, Entrevista cedida a pesquisadora em jan. de 2014).

Nos últimos anos, além deste, os coletivos que se destacaram em produções na cidade foram o Coletivo (dês)esperar; Sala Dobradiça; e o grupo Subsoloart, sendo que este

Revista Digital do LAV - Santa Maria - vol. 8, n. 2, p. 190 - 213. - mai./ago. 2015 ISSN 1983 - 7348 http://dx.doi.org/10.5902/1983734819872 
último trabalha diretamente com grafite. Outros projetos e intervenções vêm acontecendo, para os quais são convidados artistas de fora da cidade, além dos artistas locais.

A obra de Kobra não se integrou diretamente às produções desses grupos e ao contexto vivenciado por eles. Mas as instalações de obras vinculadas à deliberação direta do poder público na escolha dos artistas para a realização de obras específicas. Situação que não é restrita a Santa Maria, mas corriqueira, pois na maior parte dos casos é o poder público que libera a verba para a realização de obras públicas. No referido município, essas escolhas são restritas a alguns artistas locais e a artistas de outras regiões, convidados pelo poder público a criarem obras para os espaços urbanos, como no caso de Kobra, que foi contratado para a realização de sua obra na cidade. Como é relatado por Tamiris Vaz, componente do Coletivo (dês)esperar,

Mais ou menos naquele mesmo período foi colocada aquela escultura que é do Amoretti essa outra aqui na entrada no arco na rótula (UFSM) e ambas foram escolhidas também pelo poder público. Por um artista que de certa forma, dentro do espaço de Santa Maria, tem um certo renome, um certo reconhecimento e de um outro que nem é artista, ele é arquiteto mas que não teve novamente a influência da população (2013).

Neste sentido, percebe-se que no que concerne ao apoio das autoridades e de empresas locais em relação ao patrocínio de verbas para a arte na cidade, ainda continua delimitado a alguns artistas de renome, e de outras cidades.

\section{Muros da Memória: de quem? Para quem?}

Inserida no projeto Muros da Memória, a obra de Eduardo Kobra em Santa Maria possibilita estabelecer vínculo com a memória da cidade, bem como com os fatores que cercam a escolha da imagem da década de 1950 para ser reapresentada.

O mural de Eduardo Kobra foi pensado através de uma fotografia de Santa Maria da década de 1950 (Fig.01). A ideia de trazer o artista para retratar em um mural a imagem antiga da cidade surgiu por parte do poder executivo municipal, com a intenção de "resgatar a memória" local como aponta Ruviaro6:

\footnotetext{
${ }^{6}$ Secretário Adjunto de turismo do Município de Santa Maria.
}

Revista Digital do LAV - Santa Maria - vol. 8, n. 2, p. 190 - 213. - mai./ago. 2015 ISSN 1983 - 7348 http://dx.doi.org/10.5902/1983734819872 
Nós fizemos uma viagem a São Paulo, para participarmos de um curso. Foi quando vimos, pela primeira vez, uma obra do Kobra, em uma das principais avenidas da cidade, embaixo de um viaduto [...] Entramos em contato com as empresas que poderiam realizar a vinda e após com o artista, que veio a Santa Maria para escolher o espaço que viria a receber a obra. Houve várias sugestões, mas o Kobra, pela arquitetura, a dinâmica do espaço, considerou que os fundos da biblioteca seria o melhor lugar (RUVIARO, em entrevista cedida à pesquisadora, em maio de 2013).

A vinda de Eduardo Kobra à cidade foi parte de um projeto da Prefeitura Municipal, de incentivo à cultura e às manifestações artísticas da cidade assim como de revitalização de parte do centro com a implantação de obras espalhadas por lugares estratégicos. Ou como aponta Roberto Chagas (2013), componente do grupo Arte Pública que faz referencia a interesses do poder público,

É que o prefeito tem uma clara intenção em investir em arte. Ele gosta da maneira como ele consegue e lógico apoiado pelas pessoas que estão a volta dele, isso é uma outra questão a ser discutida. O que parece que logo que ele assumiu, ele quis marcar essa posse com uma obra que chamasse a atenção. Ele procurou artistas que ele conhecia, ou que foram indicados a ele. Essa situação, não é porque o Kobra veio que mudou alguma coisa, é que essa administração que trouxe o Kobra já estava com uma inclinação a mudar, a investir mais (Idem).

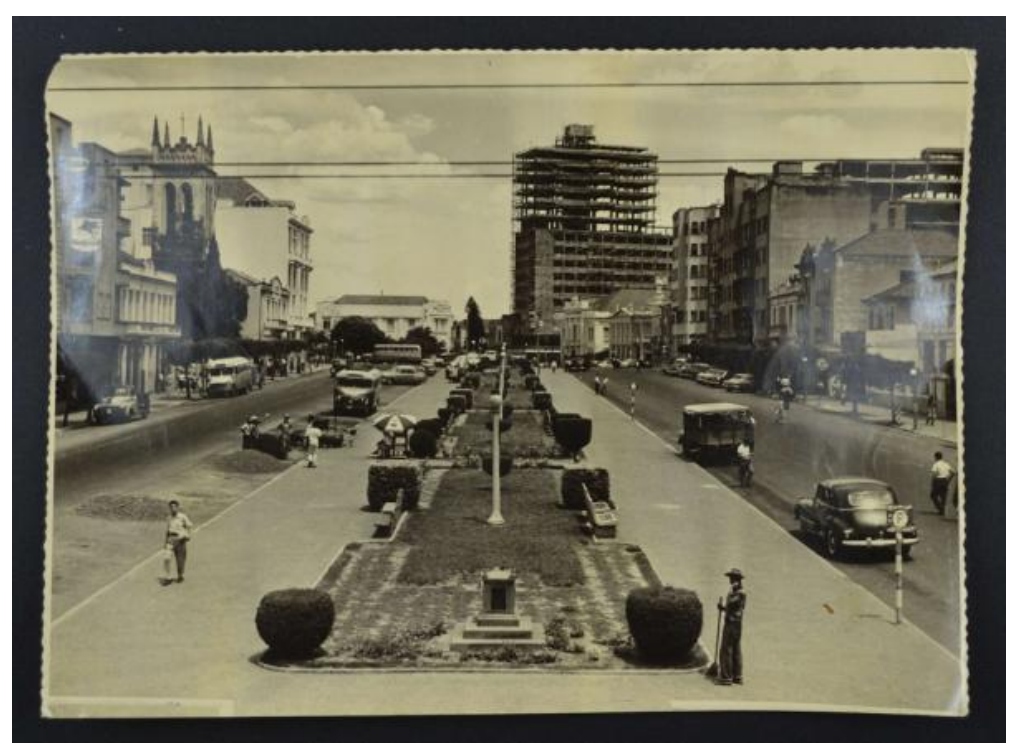

Figura 01. Vista parcial da Avenida Rio Branco, da década de 1950. Imagem usada como referência para o mural de Kobra em Santa Maria (Acervo do Arquivo Histórico de Santa Maria).

Peixoto (2012) faz uma breve reflexão sobre esse contexto entre poder público e Arte Pública, em que esta é usada para dinamizar os espaços urbanos das cidades, não no

Revista Digital do LAV - Santa Maria - vol. 8, n. 2, p. 190 - 213. - mai./ago. 2015 ISSN 1983 - 7348 http://dx.doi.org/10.5902/1983734819872 
sentido de ser exposta como obra de arte, mas em articulação e como parte de um planejamento de relembrança. A obra passa a fazer parte desse sistema socioeconômico, onde ela está inscrita e, desse modo, o artista trabalha segundo as normas de encomenda. Com isso, a Arte Pública passa a ser vista pelos mesmos critérios das obras criadas para instituições privadas, perdendo a relação com a cidade (ALVES, 2011).

O trabalho de Kobra em Muros da Memória traz essa ideia de vinculação entre o passado e o presente, por sua poética que objetiva criar e/ou possibilitar uma integração entre o público e a cidade no contexto contemporâneo, na medida em que o fluxo dos grandes centros, muitas vezes pode ser passageiro, momentâneo, limitando o tempo do conhecer e reconhecer o espaço onde se vive. Ao proporcionar, um outro olhar para a cidade, que não o das imagens tradicionais dos prédios, das ruas, do dia-a-dia, mas um perceber-se no conjunto, seja por obras contemporâneas que proporcionam essa percepção (PEIXOTO, 2012), seja por obras, como os murais de Kobra, que dialogam com os espaços.

Enquanto o artista objetivava uma relação identitária entre os sujeitos e a cidade, pela representação de um passado local, a administração de Santa Maria buscou, com a produção da obra em uma das avenidas mais movimentadas da cidade, a Avenida Presidente Vargas, uma aproximação com a população, conectando, assim, um passado "vivido e relembrado pelos agentes da administração" a um conjunto de interesses que se conjugam dentro de um processo contemporâneo de inclusão, de conceito de perfeição, de integração onde todos fazem parte, sem exclusões ou diferenças (Idem, 2012).

No caso específico da obra de Kobra, essas relações só foram possíveis pela utilização de fotografias de épocas, registros guardados como patrimônios de tempos pretéritos que "buscam ser revividos" em um processo que muitas vezes é alicerçado pelas "reminiscências e do qual é utilizado para proporcionar um ideal de progresso, que, no entanto, não pode deixar de lado sua história" (DUARTE, 2009, p. 305).

A fotografia apresenta a Avenida Rio Branco, uma das mais importantes do centro da cidade, que liga a Antiga Estação Férrea à Rua do Acampamento, a principal via de acesso ao centro, consistindo na primeira rua responsável pela povoação de Santa Maria, por volta de 1797, no entorno da atual Praça Saldanha Marinho. No logradouro, foi instalado um comércio forte, que abastecia as famílias e a população local com produtos primários e lojas de produtos variados, além de bancos, escolas e igrejas. Paralelo ao

Revista Digital do LAV - Santa Maria - vol. 8, n. 2, p. 190 - 213. - mai./ago. 2015 ISSN 1983 - 7348 http://dx.doi.org/10.5902/1983734819872 
desenvolvimento da cidade e da ostentação de casas e prédios no centro e nas ruas principais localizava-se a periferia, com casas de madeiras, sem sanitários e/ou espaço para horta e criação de animais, e em más condições.

Desta forma, destacaram-se imagens que mostravam ruas organizadas, pessoas caminhando descontraídas, carros e ônibus transitando pelas Avenidas, em registros fotográficos que idealizam imagens de prosperidade, de desenvolvimento econômico e social, evidenciando os cuidados dos gestores com a população e o urbanismo, propiciando uma visibilidade positiva perante os governos estaduais e nacionais, além de um estímulo para a imigração da população para a cidade. Pois, "Em toda a sua extensão, existiam casarões elegantes e construídos com esmero, geralmente com platibanda e fileiras de sacadas de balaústres" (FOLETTO org., 2008, p. 46).

A Avenida Rio Branco teve seu tempo de auge e prosperidade, que aos poucos foi estagnando-se e perdendo sua importância para outras avenidas, como no caso, a Presidente Vargas, onde a obra contextualizada foi instalada. Conjugando-se em uma relação entre passado e presente "num sentido de progresso" para seus contratantes. Pois, a escolha da imagem não partiu diretamente do artista, mas do poder público. 0 qual selecionou doze imagens da cidade, que foram apresentadas ao artista para a definição da que seria pintada no mural. Dessas doze, nove são imagens da mesma avenida. Neste sentido, é possível pensar que a Avenida Rio Branco faz parte de uma memória histórica, coletiva e material da cidade, por nela estarem inseridas histórias. Neste contexto considera-se que as memórias e histórias só podem ter um sentido, significado, tanto individual quanto coletivamente quando imbricadas a fatos e momentos que tiveram e/ou ainda têm relevância para a formação social ou histórica de cada sujeito. Essas memórias produzidas por esses indivíduos ou grupos são carregadas de sentimentos oriundos dos fatos passados, que se deixam transparecer nos relatos desses tempos, seja por suas representações simbólicas, culturais, individuais, sociais e coletivas (DIEHL, 2006).

Paralela a essa visão de inserção de atrelamento entre memória e presente está inserida a Avenida Presidente Vargas, por nela estarem instaladas escolas, igrejas e o maior hospital da cidade. É também nesta direção que está localizado o Museu Vicente Pallotti, junto à Faculdade Palotina de Santa Maria, o Museu de Arte de Santa Maria (MASM) ${ }^{7}$, a Sala de Exposições Iberê Camargo, no prédio do Arquivo Histórico Municipal e a Biblioteca Municipal Henrique Bastide. Estes espaços destinados ao desenvolvimento

\footnotetext{
7 Criado em 1992.
}

Revista Digital do LAV - Santa Maria - vol. 8, n. 2, p. 190 - 213. - mai./ago. 2015 ISSN 1983 - 7348 http://dx.doi.org/10.5902/1983734819872 
cultural agregam-se pela proximidade e entorno com o espaço de lazer, conhecido como "Largo da Locomotiva", onde estão localizadas a escultura Vento Norte, algumas esculturas em pedra (resultantes do $1^{\circ}$ Encontro de Escultores de Santa Maria, ocorrido em 2011), uma máquina de trem e o mural de Eduardo Kobra, aos fundos da referida Biblioteca. Ou como foi analisado por Kobra, "vi vários locais interessantes, até me mostrarem a biblioteca, queriam me dar várias opções. Considerei que o melhor painel seria ali, na biblioteca, com todas as condições, com a praça, os lugares de exposição, com a revitalização da praça" (2013).

Neste sentido, insere-se o mural de Kobra, que retrata um espaço público que estabelece relações entre passado e presente, entre história contada e vivida, a partir de uma obra que discute conceitos e valores da cidade, onde o novo se apropria do antigo, substituindo-o, porém, com a possibilidade de integrá-los a partir da memória. Ligada as histórias da cidade que se constitui em relação com a comunidade e o público. Nessa conjuntura, a obra deixa de ser imposta, pois, como é tratado por Alves "elas devem possibilitar o exercício da reflexão de seus cidadãos em relação não só a arte, mas a um conjunto de relações entre o indivíduo e a sociedade" (2005, p. 35).

O autor discorre sobre o conjunto social, do qual a arte faz parte e os artistas se valem para suas pesquisas e poéticas, obras que intencionam um olhar para o contexto das comunidades (SILVA, 2006). Kobra propõe uma observação da cidade, com a imagem que conta uma história, que vai além da moldura do mural, ao perpassar por um contexto, um processo de enraizamento dos sujeitos sociais que contribuíram ou mesmo vivenciaram os tempos de outrora e que, de algum modo, refletiram na Santa Maria de hoje, ao se constituir em imagens que lembram o que não existe mais.

Freire (1997) argumenta que a memória é movida pela vinculação entre a ausência das imagens e da arquitetura citadina antiga, que é fruto de um processo cultural produzido por paradigmas da cultura do consumo e do novo, que é questionável e vem sendo tratado tanto no âmbito social, científico quanto artístico. Neste, por artistas como Kobra ou/e em eventos como Arte\#Ocupa Santa Maria, intentando alternativas que produzam elos entre o patrimônio das cidades com a modernidade social e arquitetônica, e, assim, possibilitando uma valorização do passado. Além de propor relações e diálogos entre artistas locais e visitantes, como relata Vaz,

Eu acho interessante esse projeto por estar buscando espaços comuns para as exposições de arte, outro por estar promovendo exposições que não são exposições que têm outro tipo de

Revista Digital do LAV - Santa Maria - vol. 8, n. 2, p. 190 - 213. - mai./ago. 2015 ISSN 1983 - 7348 http://dx.doi.org/10.5902/1983734819872 
proposta, que é uma proposta da modificação da adaptação e do diálogo. Que não tem um planejamento, oportunizando a chance de se modificar, por trazer artista de fora e não só os artistas daqui (Entrevista cedida à pesquisadora em dezembro de 2013).

A obra de Kobra, no entanto, foi pensada a partir de interesses particulares do poder público municipal, com o objetivo de agregação e também de propiciar acesso à cultura local, o que, aos poucos, foi sendo captado pela população, ou por uma parcela, que a incorporou como elemento de suas histórias e de seu patrimônio social, pela identificação que o público concebeu com a imagem, tanto em seu espaço contemporâneo, físico quanto com a história que pertence a ambos: obra, público e cidade. O artista, ao delimitar sua escolha pela imagem, levou em consideração o vínculo entre a representação da população na atualidade e na década de 1950, como meio de identificação entre os espaços de convivência, a mobilidade urbana das duas avenidas, ou mesmo da produção de "imaginações" referentes àquele tempo. São processos, possibilidades que a fotografia e a Arte Contemporânea engendram e o espaço público, a partir de obras em Arte Pública, aproxima ou condiciona à população que transita por esse espaço ou vive no seu entorno. Porém com o mesmo intento de comunicar, educar, uma vez que toda obra propõe e pode constituir relações e interpretações que, de alguma maneira, dizem ou exprimem algo a quem tem contato com ela.

\section{Disparidades no cenário da Arte Pública em Santa Maria na atualidade}

Atualmente, quatro grupos desenvolvem diretamente suas produções, visando os espaços públicos: Arte Pública, Coletivo (Des)esperar, Sala Dobradiça e Subsolo Art. Além destes, há outros grupos que desenvolvem atividades no campo das artes visuais na cidade: um que corresponde a um espaço alternativo de exposição em uma casa na Cohab Fernando Ferrari, no Bairro Camobi, denominado de Ateliê casa 9. Outro, o grupo Momentos-específicos, que organiza eventos anuais, denominado Arte\#ocupaSM, sob a curadoria de Rebeca Stumm. Cujo evento tem como objetivo a interação entre artistas locais e obras de regiões do Brasil e do estrangeiro para desenvolverem suas produções nos espaços urbanos da cidade e discutir sobre arte.

Acerca das atividades realizadas por estes grupos, sabe-se que atualmente, no Brasil, segundo Alves não há um comissionamento direcionado à Arte Pública, uma vez que se caracterizam como "eventos pontuais, arraigados às comemorações públicas" (2011, p. 42). Paralelamente a esses eventos, alguns grupos ou entidades têm realizado eventos

Revista Digital do LAV - Santa Maria - vol. 8, n. 2, p. 190 - 213. - mai./ago. 2015 ISSN 1983 - 7348 http://dx.doi.org/10.5902/1983734819872 
que objetivam a inserção de obras públicas nas cidades, entre eles pode ser lembrado o projeto desenvolvido em Porto Alegre, Espaço Urbano, Espaço Arte, realizado entre 1999 e 2002.

Em Santa Maria, o Grupo Arte Pública criou um evento, que já conta com três edições, que é o "Simpósio de Escultores", realizado em 2011, em dezembro de 2013 e janeiro de 2015. No referido evento, artistas locais, nacionais e internacionais são convidados a realizar esculturas, que posteriormente à mostra, são doadas à cidade, como aborda Catiuscia Dotto, integrante do Grupo Arte Pública: "o importante é que acaba criando um patrimônio artístico, porque as obras que são produzidas por esses artistas, ficam para a cidade, elas pertencem à comunidade" (Entrevista cedida à pesquisadora em fev. 2014). Em 2012, o Grupo Arte Pública, juntamente

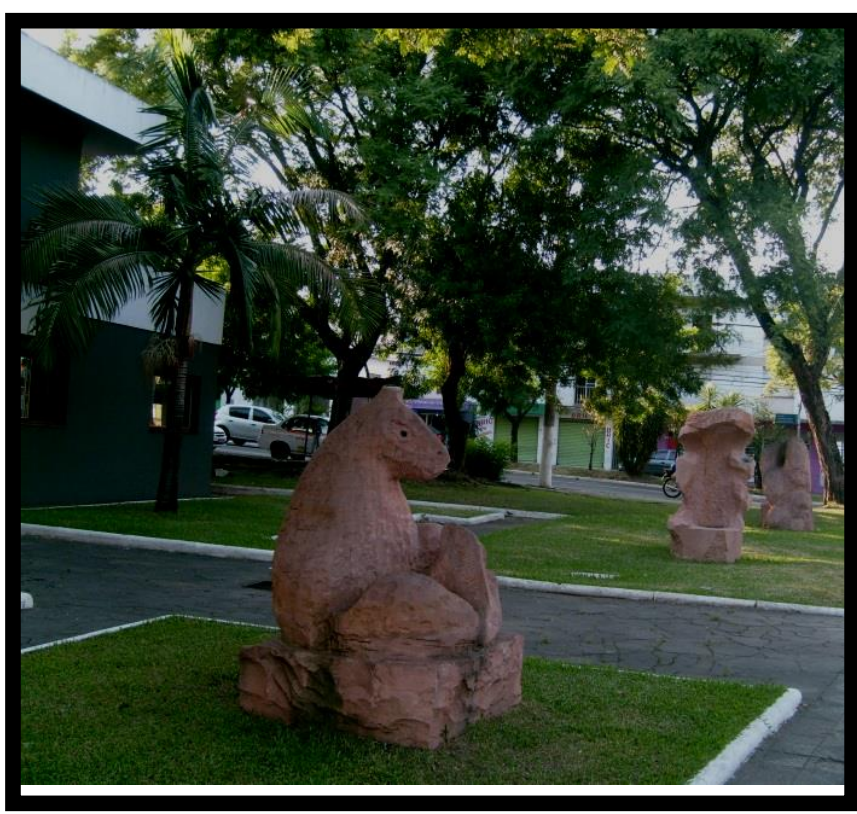

com a Associação de Artistas Plásticos
Figura 02. Esculturas em pedra do $1^{0}$ Simpósio de Escultores em Santa Maria2011. Expostas no Largo da Locomotiva, na Avenida Presidente Vargas (arquivo da pesquisadora).

realizaram o projeto "Arte no Contêiner"8 (JACQUES, 2012). Em cujo projeto foram pintados os contêineres que ficam nas ruas do centro da cidade, projeto esse financiado pela Secretária de Cultura do Município.

Ao mesmo tempo, que esses eventos vêm acontecendo, paralelamente são destacados pelos grupos pontos de divergência em relação aos projetos de incentivo à arte na

\footnotetext{
${ }^{8}$ Estas intervenções nos coletores de lixo da cidade remetem a dois projetos realizados anteriormente, um, especificamente, em São Paulo, também no ano de 2012, com o projeto Call Paredes (O Estado de São Paulo, 19 abr. 2012).
}

Revista Digital do LAV - Santa Maria - vol. 8, n. 2, p. 190 - 213. - mai./ago. 2015 ISSN 1983 - 7348 http://dx.doi.org/10.5902/1983734819872 
cidade: "é justamente, existe investimento, ele é forte... mas parece que não é continuo. Ele é muito intenso num momento, entretanto, sem continuidade" (CHAGAS, 2014. Entrevista cedida à pesquisadora em fev. 2014). O artista, também componente do Grupo Arte Pública, se refere à instalação de três obras em grandes dimensões no ano de 2010, em pontos estratégicos da cidade. Após a inserção dessas obras houve poucos incentivos direcionadas à Arte Pública na cidade, entre eles, as três edições do Simpósio de Escultores (Figura 02), cujas esculturas foram doadas a cidade ${ }^{9}$. Situação que é corroborada pelos demais grupos no decorrer das entrevistas,

São obras que têm um interesse estético, têm uma lógica artística que ela é bem predominante nessa cidade. É uma lógica mais formal, mais voltada a uma arte modernista, bem a área do Amoreti... Onde alguém do poder público chega e impõe (MACHADO ${ }^{10}$, entrevista cedida à pesquisadora em dezembro de 2013).

A crise referente à implantação de obras nos espaços públicos das cidades não se restringe a Santa Maria. Projetos são desenvolvidos, leis são criadas, mas sua implantação, quando acontece, é por tempo restrito, como aborda Alves (2011), em muitos desses casos, as comunidades artísticas não se manifestam. Kobra, em uma de suas entrevistas, também fala sobre as dificuldades de produzir obras nos espaços urbanos. Dando como exemplo a cidade de São Paulo,

[...] mesmo quando a pintura é doada, em comemoração a alguma data importante da cidade de São Paulo. Temos que enviar a prefeitura uma solicitação pedindo a liberação para pintar em um determinado muro. Para cada espaço tem que ser feito separadamente as solicitações. A tramitação dura em torno de um ano e nem sempre conseguimos a liberação. No caso do muro na Avenida 23 de Maio, o processo durou em torno de quatro meses. Quando conseguimos a liberação ela é por tempo indeterminado (KOBRA, 2013).

Segundo ele, problemas surgem quando não conseguem autorização para suas produções,

Um exemplo bem recente sobre essa situação e que acontece constantemente, é um Mural pintado pelos Gêmeos em colaboração com outros grafiteiros, em critica às manifestações

\footnotetext{
${ }^{9}$ O primeiro em 2011, o segundo em 2013 e o terceiro em janeiro de 2015.

${ }^{10}$ Fábio Machado, componente do Coletivo (Dês) esperar.
}

Revista Digital do LAV - Santa Maria - vol. 8, n. 2, p. 190 - 213. - mai./ago. 2015 ISSN 1983 - 7348 http://dx.doi.org/10.5902/1983734819872 
ocorridas no país durante o primeiro semestre deste ano. Após o mural ser grafitado, os funcionários da prefeitura foram lá e pintaram todo o muro com tinta cinza. Essa é uma prática recorrente aqui em São Paulo para tentar inibir os grafiteiros de pintar nos muros. Os Gêmeos estão produzindo um documentário com o tema "Cidade cinza" (Idem, 2013).

São restrições, como pude observar tanto na fala de Kobra, quanto na Tese de Alves (2011) e em outros artigos, em grande parte do país. Santa Maria faz parte dessa realidade, pois não há uma política pública para arte e a Arte Pública na cidade, que envolvam as empresas locais, como é apontado por Machado sobre a questão, "fica essa sensação de que é um campo privilegiado, que é um campo que também não tem a consulta ao público, onde há falta de diálogo. Aonde alguém do poder público chega e impõe" (2013).

Alessandra Giovanella, componente do Grupo Sala Dobradiça, trata da participação do grupo na $8^{a}$ Bienal do MERCOSUL, em 2009, e da falta de reconhecimento para com os grupos locais, mesmo quando estes são reconhecidos fora do contexto santa-mariense,

Quanto ao poder público local, há falta de visão e de acompanhamento do que de fato se dá como cultura na cidade. Para se ter uma ideia, o poder público não reconhece que houve uma atividade da $8^{a}$ Bienal do Mercosul em Santa Maria, realizada pelo nosso Grupo, por exemplo, na redação do Plano Municipal de Cultura, não há menção a essa atividade e nem à existência do Grupo, (Entrevista cedida à pesquisadora em Nov. 2013).

Os relatos dos dois artistas apontam para um isolamento, que delimita à arte local, e de uma possível falta de conhecimento sobre os artistas locais, ou uma seleção deliberada por algumas pessoas. Outro ponto importante destacado pelos grupos e/ou artistas é a "preferência" dada pela administração municipal por alguns artistas e obras, como abordou Machado (2013) na citação anterior.

Ao investigar o contexto artístico local e as entrevistas, em alguns momentos parece que existem dois percursos bem divergentes, um vinculado a um grupo fomentador que delimita a inserção e as verbas para alguns artistas com certo reconhecimento, deixando à margem os artistas mais jovens, recém - formados pela instituição acadêmica. Sob este aspecto, alguns artistas locais evidenciam o descontentamento, por terem seus

Revista Digital do LAV - Santa Maria - vol. 8, n. 2, p. 190 - 213. - mai./ago. 2015 ISSN 1983 - 7348 http://dx.doi.org/10.5902/1983734819872 
trabalhos reconhecidos em outras cidades e espaços de exposição, como é o caso do Grupo Sala Dobradiça, que já participou em duas Bienais do MERCOSUL:

Uma participação no Programa de Residências Artistas em Disponibilidade, Santa Maria/RS, da 7a Bienal do Mercosul 2009, em outubro de 2009, como apoiadora do projeto Clube do Desenho / Sala de Ensaios da artista argentina Claudia del Rio (Rosário/Argentina); [...] e em 2011, participou como convidada do Projeto Curatorial Continentes - $8^{a}$ Bienal do Mercosul - Ensaios de Geopoética, desenvolvendo o projeto Espaço Recombinante (GIOVANELA, 2013).

O Coletivo (Des)esperar "teve projetos desenvolvidos para a Bienal do Esquisito, em 2010 [...]; na Bienal de Cultura e Arte da UNE, Mostra CUCA, no Aterro do Flamengo, Rio de Janeiro, entre 19 e 21 de janeiro de 2011" (MACHADO, 2013, e informações retiradas do site do coletivo).

Da mesma forma, o grupo Arte Pública tem participado de vários eventos pelo país e no estrangeiro, em escultura. Recentemente estiveram no Chile, participando de um Simpósio de Escultores na cidade de Valdivia. Os quatro grupos entrevistados têm trabalhos reconhecidos e premiados em outros circuitos artísticos, mas, na cidade, os três primeiros têm pouca visibilidade e apoio, inserindo-se, dessa forma, em outras malhas de rede, entre grupos, cidades e instituições artísticas. Contudo, essa rede não transita pelo circuito artístico local, não recebendo visibilidade e incentivo para suas produções.

Os investimentos em cultura e em artes são muito restritos, tanto no que se refere a eventos artísticos e/ou à produção de obras públicas. A maior parte dos projetos que são desenvolvidos por coletivos resultam de recursos próprios, "em geral os trabalhos são de forma autônoma, mesmo quando somos convidados" (TOLEDO, 2014. Entrevista cedida à pesquisadora, em fev. 2014).

O único grupo que tem diálogo direto com o poder público municipal é o Grupo Arte Pública, mas como já foi referido anteriormente, não é algo de fácil acesso e requer muito trabalho e flexibilidade. São restrições propositais, pois os investimentos direcionados à arte são para obras fixas e tradicionais. Os grafites não fazem parte desses investimentos, acredito, por estarem vinculados, de certo ponto de vista, à

Revista Digital do LAV - Santa Maria - vol. 8, n. 2, p. 190 - 213. - mai./ago. 2015 ISSN 1983 - 7348 http://dx.doi.org/10.5902/1983734819872 
pichação e a certa insegurança no que se refere a uma perda de controle, se autorizado e incentivado. Obras efêmeras, como instalações temporárias e intervenções são passageiras, não abarcando o grande público, tanto pela falta de conhecimento como pela própria efemeridade das obras.

No que concerne à obra de Kobra na cidade, as críticas são tão enfáticas quanto às referentes ao poder público. Primeiro é tratado pela questão da imposição da obra para o público, tanto na linguagem, temática e do artista escolhido, como pela forma como ocorreu sua escolha. O isolamento do autor da obra e a falta de diálogo, tanto dele quanto do poder público para com a comunidade, a própria linguagem escolhida, valor, interesses particulares por parte da administração. Ao valor pago a obra e o seu estado de deterioração em apenas quatro anos (Fig. 03).

Em Santa Maria essas divergências afloraram tanto pela falta de diálogo, trocas, interação e por uma busca pela demarcação de territórios e interesses. Interesses que

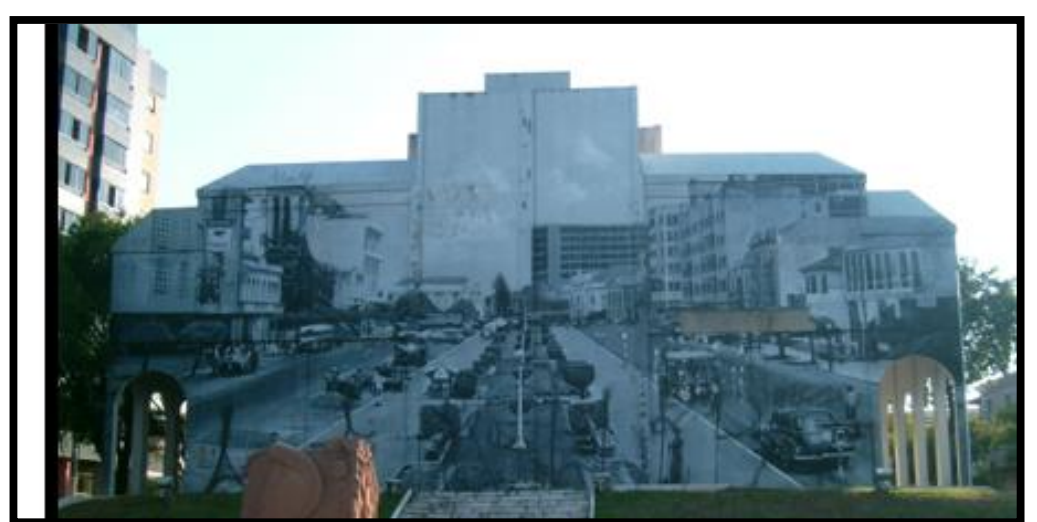

desconsideram diretamente o público, quando este só
Figura 03. Mural de Eduardo Kobra em Santa Maria nos fundos da Biblioteca Pública Municipal, $2010 . \quad$ Arquivo particular da pesquisadora.

fica ciente de instalações de obras nos espaços urbanos quando elas já estão lá. Essa falta de interação se faz em ambos os campos, tanto político quanto artístico. No primeiro caso, pela imposição direta.

No caso específico, esses desacordos foram intensificados com a imposição de uma obra, produzida por um artista de fora, e pelo valor pago a ele. No que concerne ao público, os discursos no que diz respeito à obra são mais amenos, houve questionamentos, certo desconforto com relação ao mural, mas também uma aceitação amena, pois a obra já estava lá, não havia como voltar atrás. A pintura já é parte da cidade, é história, é memória. Como já foi abordado por vários autores citados, as obras nos espaços públicos estão e são sujeitas a diferentes interpretações e críticas, que contribuem com sua

Revista Digital do LAV - Santa Maria - vol. 8, n. 2, p. 190 - 213. - mai./ago. 2015 ISSN 1983 - 7348 http://dx.doi.org/10.5902/1983734819872 
eternização, pois uma obra, que ao ser exposta em um espaço e não produz reflexões, torna-se uma obra vazia para o contexto onde foi instalada.

A obra de Kobra em Santa Maria, ao contrário, tem facultado, desde 2010, questões pertinentes à arte na cidade, que estão sendo ampliadas a outras obras, envolvendo a comunidade artística e as autoridades. Contudo, tratadas isoladamente, cada um com seus argumentos e interesses, sem um consenso. No que diz respeito à vinda súbita do artista, sua estada na cidade poderia ter sido transversalizada por palestras, encontros com Kobra, tanto das escolas, quando com os artistas locais. Falha essa que não se deve somente ao poder público, como também por parte dos próprios artistas locais (constatação advinda das falas dos artistas).

O que pude perceber, ao analisar o mural de Kobra na cidade, foi um certo desconforto por parte de algumas pessoas, afirmando que a vinda do artista não contribuiu para suas produções e tampouco para a Arte Pública local. Mas propiciou posicionamentos críticos por parte do público para com a cidade, e o que é nela exposto. E também por parte da comunidade artística, que internamente tem questionado a postura da prefeitura e das empresas locais, vinculada ao campo artístico.

[...] projeto dos "Encontros de escultores" da estação, organizado pelo grupo "Arte Pública". Esses encontros estão envolvendo gente que está na graduação de Artes Visuais, que está trabalhando com essas questões. Que pode ser que, ao estar trabalhando com aquela situação ali, eles possam estar se apropriando um pouco dos discursos de como se inserir nesse patamar do poder público e tentar fazer e se colocar ali dentro, tentar se inserir, tentar descobrir os meios de se colocar ali e de convencer o poder público a incentivar a sua arte (MACHADO. Entrevista cedida à pesquisadora, em dez. 2013).

Machado (2013), componente do Coletivo (des)esperar, interpõe sobre uma realidade que pode ser repensada através de articulações que envolvam e que partam dos princípios onde as diferenças e divergências devem ser amenizadas em prol de todos: artistas, comunidade, governo, a cultura e a arte. São questões complexas, onde alteridade deve se integrar ao diálogo, em um sentido abrangente em relação aos diferentes pensamentos, produções artísticas e grupos e mesmo entre estes, considerando as responsabilidades de cada setor e seu papel junto à comunidade e as obras na cidade, valorizando as produções locais. Aos fomentadores e promotores da

Revista Digital do LAV - Santa Maria - vol. 8, n. 2, p. 190 - 213. - mai./ago. 2015 ISSN 1983 - 7348 http://dx.doi.org/10.5902/1983734819872 
arte, segundo Alessandra Giovanela, componente do Grupo Sala Dobradiça, é importante que eles busquem um maior conhecimento sobre os grupos.

São grupos que têm produções efêmeras, desenvolvem projetos que buscam integrar a comunidade e as escolas, que estão além da "arte oficial", por produzirem nas ruas, mesmo sem incentivo, por buscarem uma aproximação com os jovens. Pequenas fendas estão se abrindo, pelo esforço e dedicação de alguns artistas locais, que aos poucos podem ganhar visibilidade, e a integração tanto de outros artistas, como do público.

\section{Considerações}

A arte local e suas influências e confluências estão vinculadas à arte nacional e internacional. Deliberar e ou impor uma obra nos espaços públicos não é algo restrito a Santa Maria, mas já vem ocorrendo em outros centros urbanos. A obra de Kobra na cidade faz parte desse sistema institucionalizado, que se integrou a um projeto local de incentivo à cultura e às artes e, ao mesmo tempo, aflorou essas questões, principalmente entre a comunidade artística local, percebendo-se, assim, a fragilidade das relações entre os promotores da arte na cidade e os artistas e grupos de artistas locais.

Concomitantemente, paralelo aos estudos sobre o mural do artista na cidade de Santa Maria, aos poucos produzi relações/aproximações. Premissa que possibilitou analisar a realidade vista por estes artistas e pelos promotores da arte e da cultura na cidade. Suas disparidades e anseios, onde os grupos demonstram perspectivas, percepções do mundo e vivências afins. Em busca de alternativas que os possibilitem uma valorização e inserção para sua arte no contexto local. Questões particulares que atingem uma dimensão, um domínio abrangente no campo artístico na cidade, que podem reverberar em discussões e mudanças de atitude, sejam por meio do diálogo com os promotores das artes que culminou em apoio a alguns projetos em arte para os espaços urbanos.

São pequenas ações que estão sendo iniciadas e que poderão possibilitar desdobramentos interessantes, pois eles não têm o intento somente de expor suas obras nos espaços, mas de produzir o diálogo e a inserção junto à comunidade. Ainda que estes fazeres sejam mais complexos e consequentemente mais lentos, mudanças não acontecem rapidamente: necessitam de atitudes e práticas atreladas à mudanças de postura e ao diálogo entre as partes.

Revista Digital do LAV - Santa Maria - vol. 8, n. 2, p. 190 - 213. - mai./ago. 2015 ISSN 1983 - 7348 http://dx.doi.org/10.5902/1983734819872 


\section{Referências}

ALVES, José F. A especificidade da Arte Pública na $5^{\mathbf{a}}$ Bienal do MERCosUL - Porto Alegre. 2011. 238 f. Tese (Doutorado em Artes) -Universidade federal do Rio Grande do Sul. UFRGS.

Arte Pública no contexto da Bienal do Mercosul (p.31-36). In: DUARTE, Paulo S. (org.) Rosa-dos-ventos: posições e direções na arte contemporânea.Org. Porto Alegre, Fundação Bienalde Artes Visuais do Mercosul, 2005.

BERGSON, Henri. Trad. NEVES, Paulo. Matéria e memória: ensaio sobre a relação do corpo com o espírito. São Paulo: wfmMartins Fontes, 2011.

CATROGA, Fernando. Os passos do homem como restolho do tempo: memória e fim do fim da história. Portugal: Biblioteca Nacional de Portugal, 2009.

DIEHL, Astor A. Com o passado na cadeira de balanço: cultura, neutralidades e subjetividade. Passo Fundo: Ed. Universidade de Passo Fundo, 2006.

DENZIN, Norman K. Trad. Sandra Regina Netz. O planejamento da pesquisa qualitativa: teorias e abordagens. Porto Alegre: ARTMED, 2006.

DUARTE, Luiz F. D. Memória e reflexibilidade na cultura Ocidental. In: ABREU, Martha e CHAGAS, Mário. Memória e Patrimônio: Ensaios Contemporâneos. 2a Ed. Rio de Janeiro: Editora Lamparina, 2009.

FOLETTO, Vani T. (org.). Apontamentos sobre a história da arquitetura de Santa Maria. Santa Maria: Pallotti, 2008.

FOLETTO, Vani T. e BISOGNIN, Edir T. As artes visuais em Santa Maria: contextos e artistas. Santa Maria: Pallotti, 2001.

FREIRE, Cristina. Além dos mapas: os monumentos no imaginário urbano e contemporâneo. São Paulo: SESC: Annablume, 1997.

PEIXOTO, Nelson B. Intervenções urbanas: Arte/Cidade. 2a Ed. São Paulo: Editora SENAC, 2012.

PELBART, Peter Pál. O tempo não-reconciliado. São Paulo: Perspectiva, 2010.

SILVA, Fernando P. Arte Pública, diálogo com as comunidades. Belo Horizonte: Editora C/ Arte, 2005.

TAMOTO, R. Para comemorar 447 anos, Pinheiros pinta o passado. Diário do Comércio. São Paulo, s/p, 8 ago. de 2007.

THOMPSON, Paul. A voz do passado-história oral. Rio de Janeiro: Paz e Terra, 2002.

\section{REFERENCIA DAS ENTREVISTAS REALIZADAS PARA A DISSERTAÇÃO}

Revista Digital do LAV - Santa Maria - vol. 8, n. 2, p. 190 - 213. - mai./ago. 2015 ISSN 1983 - 7348 http://dx.doi.org/10.5902/1983734819872 
CHAGAS, R. Roberto Chagas. Entrevista [fev. 2014]. Entrevistador: M. T. UBERTI. Santa Maria: UFSM; um CD. Entrevista cedida ao projeto de Mestrado o mural de Eduardo Kobra em Santa Maria: uma relação com a Arte Pública, pelo PPGART.

DOTTO, C. Catiuscia Dotto. Entrevista [fev. 2014]. Entrevistador: M. T. UBERTI. Santa Maria: UFSM; um CD. Entrevista cedida ao projeto de Mestrado o mural de Eduardo Kobra em Santa Maria: uma relação com a Arte Pública, pelo PPGART.

GIOVANELLA, A. Alessandra Giovanella. Entrevista [nov. 2013]. Entrevistador: M. T. UBERTI. Santa Maria: UFSM; um CD. Entrevista cedida ao projeto de Mestrado o mural de Eduardo Kobra em Santa Maria: uma relação com a Arte Pública, pelo PPGART.

KOBRA, E. Eduardo kobra. Entrevista [abr. 2013]. Entrevistador: M. T. UBERTI. São Paulo: Stúdio Kobra; um CD. Entrevista cedida ao projeto de Mestrado o mural de Eduardo Kobra em Santa Maria: uma relação com a Arte Pública, pelo PPGART.

MACHADO, F. P. Fábio Puper Machado. Entrevista [DEZ. 2013]. Entrevistador: M. T. UBERTI. Santa Maria: UFSM; um CD. Entrevista cedida ao projeto de Mestrado o mural de Eduardo Kobra em Santa Maria: uma relação com a Arte Pública, pelo PPGART.

RUVIARO, R. Rafael Ruviaro. Entrevista [maio. 2013]. Entrevistador: M. T. UBERTI. Santa Maria: Secretária de Turismo; um CD. Entrevista cedida ao projeto de Mestrado o mural de Eduardo Kobra em Santa Maria: uma relação com a Arte Pública, pelo PPGART.

Vaz, T. Tamiris Vaz. Entrevista [DEZ. 2013]. Entrevistador: M. T. UBERTI. Santa Maria: UFSM; um CD. Entrevista cedida ao projeto de Mestrado o mural de Eduardo Kobra em Santa Maria: uma relação com a Arte Pública, pelo PPGART.

\section{Referências Digitais}

CUNHA, Caroline. Eduardo Kobra, um muralista da arte urbana. São Paulo: Saraiva, 2012. Disponível em: http://www.saraivaconteudo.com.br/Materias/Post/46117. Acesso em 30 abr. 2013.

GONTOW, Airton. Arte Urbana: Eduardo Kobra avança em sua 'maior obra', 2012. Disponível em: http://miriampetrone.com.br/oquemaisacontece/archives/6745. 29 mai. 2013.

JACQUES, Vera. Arte Contêiner: coletores ganharam pintura de artistas santamarienses neste sábado. Santa Maria: 2012. Disponível em: http://www.santamaria.rs.gov.br/noticias/5170. Acesso em 12 dez. 2012.

Enviado em: Janeiro de 2014

Aprovado em: Julho de 2015.

\footnotetext{
i Possui graduação em Artes Visuais - Licenciatura em Desenho e Plástica, pela Universidade Federal de Santa Maria (2010) atuando principalmente nos seguintes temas: cultura, arte pública, educação das artes visuais e intervenção. Bolsita Capes - PIBID - Programa Institucional de Bolsa de Iniciação a Docência, no sub-projeto "Arte pública" (2010). Pós-graduação em Gestão Escolar pela Universiade Cidade de São Paulo (2012). Mestre pelo PPGART/UFSM em Arte e Cultura (2014). Professora de Artes na rede municipal de ensino de Santa Maria, RS. Email: maritaschetto@hotmail.com
}

Revista Digital do LAV - Santa Maria - vol. 8, n. 2, p. 190 - 213. - mai./ago. 2015 ISSN 1983 - 7348 http://dx.doi.org/10.5902/1983734819872 
Mariete Tasquetto Uberti

Revista Digital do LAV - Santa Maria - vol. 8, n. 2, p. 190 - 213. - mai./ago. 2015 ISSN 1983 - 7348 http://dx.doi.org/10.5902/1983734819872 